\title{
Effect of loading time on marginal bone loss around hydroxyapatite-coated implants
}

\author{
Young-Kyun Kim ${ }^{1,5}$, Kyo-Jin Ahn', Pil-Young Yun ${ }^{1}$, Minkyoung Kim², \\ Hong-So Yang ${ }^{2}$, Yang-Jin Yi ${ }^{3}$, Ji-Hyun Bae ${ }^{4}$ \\ ${ }^{l}$ Department of Oral and Maxillofacial Surgery, Section of Dentistry, Seoul National University Bundang Hospital, Seongnam, \\ ${ }^{2}$ Department of Dental Science, School of Dentistry, Chonnam National University, Gwangju, ${ }^{3}$ Department of Prosthodontics, Section of \\ Dentistry, Seoul National University Bundang Hospital, Seongnam, ${ }^{4}$ Department of Conservative Dentistry, Section of Dentistry, \\ Seoul National University Bundang Hospital, Seongnam, ${ }^{5}$ School of Dentistry, Seoul National University, Seoul, Korea
}

\begin{abstract}
J Korean Assoc Oral Maxillofac Surg 2013;39:161-167)
Objectives: The objective of this study is compare the rate of marginal bone resorption around hydroxyapatite-coated implants given different loading times in order to evaluate their stability.

Materials and Methods: The study was conducted retrospectively for one year, targeting 41 patients whose treatment areas were the posterior maxilla and the mandible. Osstem TS III HA (Osstem Implant Co., Busan, Korea) and Zimmer TSV-HA (Zimmer Dental, Carlsbad, CA, USA), which employ the new hydroxyapatite coating technique, were used. The patients were divided into two groups - immediate and delayed loading - and the bone level at the time of loading commencement and after one year of loading was measured using periapical radiography. Differences between the groups were evaluated using Mann-Whitney $(\alpha=0.05)$.

Results: For all patients as a single group, the survival rate of the implants was $100 \%$, and the mean marginal bone loss was $0.26 \pm 0.59 \mathrm{~mm}$. In comparison of the differences by loading, mean marginal bone loss of $0.32 \pm 0.69 \mathrm{~mm}$ was recorded for the immediate loading group whereas the delayed loading group had mean marginal bone loss of $0.16 \pm 0.42 \mathrm{~mm}$. However, the difference was not significant $(P>0.05)$.

Conclusion: Within the limited observation period of one year, predictable survival rates can be expected when using immediately loaded hydroxyapatite-coated implants.
\end{abstract}

Key words: Loading, Bone loss

[paper submitted 2013. 7. 23 / revised 2013. 8. 9 / accepted 2013. 8. 9]

\section{Introduction}

Osseointegration is the most important factor in successful implant treatment. In the early stage, machined surface implants using pure titanium were reported to have achieved

\footnotetext{
Ji-Hyun Bae

Department of Conservative Dentistry, Section of Dentistry, Seoul National University Bundang Hospital, 82 Gumi-ro 173beon-gil, Bundang-gu, Seongnam 463-707, Korea

TEL: +82-31-787-7541 FAX: +82-31-787-4068

E-mail:kyk0505@snubh.org

(C) This is an open-access article distributed under the terms of the Creative Commons Attribution Non-Commercial License (http://creativecommons.org/licenses/by-nc/3.0/), which permits unrestricted non-commercial use, distribution, and reproduction in any medium, provided the original work is properly cited.

Copyright (C) 2013 The Korean Association of Oral and Maxillofacial Surgeons. All rights reserved.
}

successful osseointegration, but there were limitations in case of low volume and quality of bony tissue ${ }^{1}$. In addressing these issues, various surface-treated implants were developed and sold to facilitate osseointegration and promote initial healing. Among them, hydroxyapatite (HA)-coated implants made by applying HA on the surface using plasma spray to generate depression, undercut, and porosity were introduced in the mid-1980s to increase osteogenesis and facilitate osseointegration $^{2}$; they were actively used in the 1990s. Note, however, that most products were terminated because many researchers reported high failure rates. Some researchers claimed that, from the long-term perspective, HA-coated implants can lose osseointegration because, if the coated surface is detached from the fixture or resorbed, the implant and bone are separated; thus becoming dynamically unstable.

This study was supported by a grant from the Korean Health Technology R\&D Project of the Ministry of Health and Welfare, Republic of Korea (A101724). 
Even with satisfactory early osseointegration, the HA-coating is easily contaminated, and this results in its resorption and subsequent failure of the implant ${ }^{3}$. Nonetheless, some researchers report that advancements in HA-coating technology have resolved these problems and produced long-term stable clinical results. Insufficient stability resulting from HA-coating desquamation and irregular coating thickness has been addressed with technological advancements such as ion plating $^{4}$ and ion sputtering ${ }^{5}$, thermal decomposition method ${ }^{6}$, and biomimetic process. Another viable option is the more recently developed thermally induced liquid-phase deposition method $^{7}$.

Another important factor in successful osseointegration following implant placement is loading. Currently, it is regarded as principle wherein a certain healing period is assigned without loading. According to Brånemark et al. ${ }^{8}$, premature loading after implant placement can generate fibrous tissue on the bone-implant interface rather than bone deposition; thus, insufficient healing period increases the possibility of early or delayed mobility of the implant. The minimum healing period suggested by Brånemark in 1977, based on 10 years' clinical experience, was 3 months for the mandibular implant and 5-6 months for the maxillary one ${ }^{8}$. Albrektsson ${ }^{9}$ stated that the most important period is the first month following implant placement. Excessive loading during this period can damage the balance between bone generation and bone resorption and result in fibrous connective tissue that interferes with osseointegration. Note, however, that the traditional healing period suggested by Brånemark may not be suitable today because the Brånemark research was based only on machined surface implant; it did not consider the implant design, surface treatment, surgical method, and biomechanical prosthesis ${ }^{10}$. Recent research on the stability of immediate and early loading reported success rates of 88$100 \%$, suggesting that the healing period after treatment will continue to decrease ${ }^{1,11,12}$.

Marginal bone height is an important factor in the implant's functional and aesthetic success, and maintaining the proper height of marginal bone is a precondition for the implant's longterm, satisfactory use. Marginal bone resorption in the boneimplant interface interferes with the stability of surrounding tissues and causes periimplantitis or mobility of the implant. Vercruyssen and Quirynen ${ }^{13}$ reported that, in their long-term research, smoking, guided bone regeneration, dehiscence defect, and bony tissue are closely related to the height of marginal bone around the implant. Based on the researchers' reports, i.e., failure of a loading implant most frequently occurs within one year of functioning ${ }^{14}$, this study measured the amount of resorption after one year of loading.

To compare the stability of HA-coated implants with different loading initiation times, two different implants that secured thinner and more even thickness of HA coating and increased crystallization rate were placed on patients: Osstem TS III HA (Osstem Implant Co., Busan, Korea) and Zimmer TSV-HA (Zimmer Dental, Carlsbad, CA, USA). After applying immediate and delayed loading based on the definition of Cochran et al. ${ }^{15}$, implant survival rate was measured according to criteria established by Buser et al. ${ }^{16}$ and Cochran et al. ${ }^{17}$ After one year of loading, the resorption amount of crestal bone was evaluated retrospectively.

\section{Materials and Methods}

\section{Materials and subjects}

This study was conducted by the Section of Dentistry at Seoul National University Bundang Hospital, following approval by the institutional review board (approval No. B-1012-117-105). We have read the Helsinki Declaration and have followed the guidelines in this investigation. The 1-year retrospective study involved a total of 41 patients (74 implants,

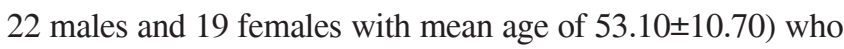
had 1 or 2 implants placed consecutively in their posterior maxilla or mandible and immediate or delayed loading between September 2010 and April 2011. Osstem TS III HA was implanted in 17 patients (33 implants), and Zimmer TSVHA (41 implants), in 24 patients.(Table 1) Patient selection criteria for implant placement were as follows: 1) patients older than 18 years whose jaw growth was finished; 2) patients with posterior teeth loss and available alveolar bone height of more than $6 \mathrm{~mm}$; 3) patients with adequate mesiodistal and horizontal available bones; and 4) patients with antagonistic tooth of placed implant. The following were the criteria for exclusion: 1) pregnant women; 2) patients who had a heart attack only recently; 3 ) patients with uncontrollable systemic disease; 4) patients with hemorrhagic disease or disease requiring the administration of anticoagulant; 5) patients with, or suspected of having, a psychological disease; 6) patients who were scheduled to undergo tooth extraction within 2 months in the placement area and patients with severe periodontal disease in the surrounding teeth; 7) patients with grade D4 bony tissue; 8) patients who need extensive bone graft; and 9) patients for which placing an implant is difficult (patients with severe oral habit such as bruxism). 
Table 1. Descriptive data for study groups

\begin{tabular}{|c|c|}
\hline Variable & Value \\
\hline \multicolumn{2}{|l|}{ Sex } \\
\hline Male & 22 \\
\hline Female & 19 \\
\hline Total & 41 \\
\hline \multicolumn{2}{|l|}{ Age (yr) } \\
\hline Male & $51.41 \pm 11.30$ \\
\hline Female & $55.05 \pm 9.91$ \\
\hline Mean & $53.10 \pm 10.70$ \\
\hline \multicolumn{2}{|l|}{ Type of loading } \\
\hline Immediate loading & 42 \\
\hline Delayed loading & 32 \\
\hline Total & 74 \\
\hline \multicolumn{2}{|c|}{ Mean period between 1 st surgery and initial loading (d) } \\
\hline Immediate loading & $1.81 \pm 0.40$ \\
\hline Delayed loading & $149.30 \pm 48.58$ \\
\hline \multicolumn{2}{|l|}{ Method of installation } \\
\hline 1-Stage method & 51 \\
\hline 2-Stage method & 23 \\
\hline Total & 74 \\
\hline \multicolumn{2}{|l|}{ Type of implant system } \\
\hline Osstem TS III HA & 33 \\
\hline Zimmer TSV-HA & 41 \\
\hline Total & 74 \\
\hline \multicolumn{2}{|l|}{ Area } \\
\hline Maxilla & 41 \\
\hline Mandible & 33 \\
\hline Total & 74 \\
\hline \multicolumn{2}{|l|}{ Implant diameter (mm) } \\
\hline 3.70 & 3 \\
\hline 4.00 & 4 \\
\hline 4.10 & 4 \\
\hline 4.50 & 6 \\
\hline 4.70 & 32 \\
\hline 5.00 & 23 \\
\hline 6.00 & 2 \\
\hline Total & 74 \\
\hline \multicolumn{2}{|l|}{ Implant length (mm) } \\
\hline 7.0 & 1 \\
\hline 8.0 & 2 \\
\hline 8.5 & 2 \\
\hline 10.0 & 59 \\
\hline 11.5 & 9 \\
\hline 13.0 & 1 \\
\hline Total & 74 \\
\hline
\end{tabular}

Values are presented as number or mean \pm standard deviation. Young-Kyun Kim et al: Effect of loading time on marginal bone loss around hydroxyapatitecoated implants. J Korean Assoc Oral Maxillofac Surg 2013

\section{Implant placement and loading}

In this study, all surgeries and prosthesis treatments were performed by 1 surgeon and 1 prosthodontist. Implants were placed according to each manufacturer's guidelines, and bone graft was performed when a small defect around the implant was noted. If the residual bone in the maxillary posterior teeth was $6-10 \mathrm{~mm}$, sinus membrane elevation and bone graft were performed using a crestal approach, and implantation was done at the same time. Based on the period
Table 2. Distribution of cases by loading period and implant system

\begin{tabular}{ccc}
\hline Loading type & Implant system & Number of implant \\
\hline Immediate loading & Osstem & 18 \\
& Zimmer & 24 \\
\multirow{3}{*}{ Delayed loading } & Total & 42 \\
& Osstem & 15 \\
& Zimmer & 17 \\
& Total & 32 \\
\hline
\end{tabular}

Young-Kyun Kim et al: Effect of loading time on marginal bone loss around hydroxyapatitecoated implants. J Korean Assoc Oral Maxillofac Surg 2013

from implant placement to loading by prosthesis, 42 implants were categorized as immediate loading (IL) group, and 32 implants, as delayed loading (DL) group. The IL group was then subdivided into 18 Osstem TS III HA implants and 24 Zimmer TSV-HA implants based on the implant system. The DL group was also subdivided into 15 Osstem TS III HA implants and 17 Zimmer TSV-HA implants.(Table 2)

Based on the definition of Ioannidou and Doufexi ${ }^{12}$, the IL group had a temporary crown restored within 48 hours as well as occlusion with the opposite tooth (after $1.81 \pm 0.40$ days on the average); final restoration was done 3-6 months after placement ( 6 months for the maxilla and 3 months for the mandible) after confirming osseointegration. The DL group had healing period of 2.8-7.9 months (5.5 months for the maxilla and 3.0 months for the mandible on the average) after placement, with final restoration and occlusion with the opposite tooth. For the temporary crown restoration of the IL group, occlusion space as wide as 1 Accufilm (Parkell, Farmingdale, NY, USA) was applied when biting slightly; occlusal contact was unavailable for lateral movement. In the final restoration of the successful IL group and DL group, occlusion space as wide as 1 Shimstock (Kocodental, Bucheon, Korea) was created when biting slightly.

\section{Measurement of implant survival rate and bone resorption}

Both the IL group and DL group visited our hospital on the initial day of loading and 1 year later for periapical radiography and to evaluate the clinical symptoms, mobility of implant, radiolucency around the implant, and status of soft tissue to determine the implants' survival rate. Using the criteria suggested by Buser et al. ${ }^{16}$ and Cochran et al. ${ }^{17}$, the implant survival rate was evaluated: a. no clinical implant mobility; b. no pain or neural problem; c. either infection around the implant is not consistent, or it has not recurred; $\mathrm{d}$. neither radiolucency around the implant nor rapid bone loss. 
To measure and compare marginal bone resorption around the implant, digital periapical radiography was taken vertically from the longitudinal axis using the parallel cone technique. Marginal bone level was measured on the mesial and distal sides of the implant, with the mean of two values regarded as representative value. Considering the fact that the distance between the threads of fixture (thread pitch) was $0.8 \mathrm{~mm}(4.5$ $\mathrm{mm}$ in diameter) or $0.9 \mathrm{~mm}$ ( $5 \mathrm{~mm}$ in diameter) for TS III HA and $0.6 \mathrm{~mm}$ for TSV, the distance from the implant platform to the first bone-implant contact (BIC) in radiographs was measured and calculated by enlargement ratio. Marginal bone loss was calculated as the difference between the values taken on the initial day of loading and values taken at 1-year prosthetic loading. Because of the submerged machined collar (1 mm band) of TSV, the placement depth of machined-toresorbable blast media junction during surgery had to be compensated when bone loss was measured at 1-year followup. This depth was subtracted from the measurement to adjust the actual bone loss of the textured surface. The difference was measured by setting 2 dots on the radiograph using IMPAX (Agfa Corp., Mortsel, Belgium) program to measure the distance. Measurement was conducted by one dentist who did not participate in the implant treatment.

\section{Statistical analysis}

After placing the HA-coated implants, data was examined to determine whether there is significant relationship between

Table 3. Mean crestal bone resorption by loading type (at 12 months' loading)

\begin{tabular}{lccc}
\hline \multicolumn{1}{c}{ Loading type } & $\begin{array}{c}\text { Number } \\
\text { of implant }\end{array}$ & $\begin{array}{c}\text { Bone loss (mm), } \\
\text { mean } \pm \text { standard } \\
\text { deviation }\end{array}$ & $P$-value* \\
\hline Immediate loading & 42 & $0.32 \pm 0.69$ & 0.260 \\
Delayed loading & 32 & $0.16 \pm 0.42$ &
\end{tabular}

*P-values were calculated with Mann-Whitney $(\alpha=0.05)$.

Young-Kyun Kim et al: Effect of loading time on marginal bone loss around hydroxyapatitecoated implants. J Korean Assoc Oral Maxillofac Surg 2013

Table 4. Mean crestal bone resorption by loading type in Osstem TS III HA (at 12 months' loading)

\begin{tabular}{|c|c|c|c|}
\hline Loading type & $\begin{array}{l}\text { Number } \\
\text { of implant }\end{array}$ & $\begin{array}{c}\text { Bone loss }(\mathrm{mm}) \\
\text { mean } \pm \text { standard } \\
\text { deviation }\end{array}$ & $P$-value* \\
\hline Immediate loading & 18 & $0.52 \pm 1.00$ & \multirow{2}{*}{0.556} \\
\hline Delayed loading & 15 & $0.11 \pm 0.20$ & \\
\hline
\end{tabular}

initial loading time, initial loading time by implant system, initial loading time by maxilla and mandible, and change of crestal bone's height after 1 year of loading using MannWhitney ( $\alpha=0.05$ ) of IBM SPSS Statistics ver. 20.0.0 (IBM Co., Armonk, NY, USA).

\section{Results}

Implant survival rate after 1 year of loading was $100 \%$, and mean bone loss of all test groups was $0.26 \pm 0.59 \mathrm{~mm}$. For the comparison based on loading time, mean bone loss of the IL group was $0.32 \pm 0.69 \mathrm{~mm}$, and that of the DL group was 0.16 $\pm 0.42 \mathrm{~mm}$, but the difference was not statistically significant $(P=0.260)$.(Table 3 ) Regarding bone loss of the IL group and delayed group receiving the Osstem TS III HA, bone loss was $0.52 \pm 1.00 \mathrm{~mm}$ and $0.11 \pm 0.20 \mathrm{~mm}$, respectively, but the difference was not statistically significant $(P=0.556)$.(Table 4) For patients receiving the Zimmer TSV-HA, bone loss of the IL group and DL group was $0.17 \pm 0.21 \mathrm{~mm}$ and $0.17 \pm$ $0.21 \mathrm{~mm}$, respectively, but the difference was not statistically significant $(P=0.338)$. (Table 5) In comparing the bone loss of IL group and DL group in the maxilla and the mandible, bone loss in the maxilla was $0.41 \pm 0.82 \mathrm{~mm}$ and $0.10 \pm 0.16$ $\mathrm{mm}$ in the IL group and DL group, respectively, but the difference was not statistically significant $(P=0.526)$.(Table 6) Likewise, in the mandible, bone loss of the IL group was 0.27 $\pm 0.61 \mathrm{~mm}$, and that of the DL group was $0.39 \pm 0.84 \mathrm{~mm}$; the difference was not statistically significant $(P=0.620)$.(Table 7)

Table 5. Mean crestal bone resorption by loading type in Zimmer TSV-HA (at 12 months' loading)

\begin{tabular}{lccc}
\hline \multicolumn{1}{c}{ Loading type } & $\begin{array}{c}\text { Number } \\
\text { of implant }\end{array}$ & $\begin{array}{c}\text { Bone loss (mm), } \\
\text { mean } \pm \text { standard } \\
\text { deviation }\end{array}$ & $P$-value* \\
\hline Immediate loading & 24 & $0.17 \pm 0.21$ & 0.338 \\
Delayed loading & 17 & $0.21 \pm 0.56$ & \\
\hline *P-values were calculated with Mann-Whitney ( $\alpha=0.05)$. \\
$\begin{array}{l}\text { Young-Kyun Kim et al: Effect of loading time on marginal bone loss around hydroxyapatite- } \\
\text { coated implants. J Korean Assoc Oral Maxillofac Surg 2013 }\end{array}$
\end{tabular}

Table 6. Mean crestal bone resorption by loading type in the maxilla (at 12 months' loading)

\begin{tabular}{lccc}
\hline \multicolumn{1}{c}{ Loading type } & $\begin{array}{c}\text { Number } \\
\text { of implant }\end{array}$ & $\begin{array}{c}\text { Bone loss }(\mathrm{mm}), \\
\text { mean } \pm \text { standard } \\
\text { deviation }\end{array}$ & $P$-value* \\
\hline Immediate loading & 16 & $0.41 \pm 0.82$ & 0.526 \\
Delayed loading & 25 & $0.10 \pm 0.16$ & \\
\hline *P-values were calculated with Mann-Whitney ( $\alpha=0.05)$. \\
$\begin{array}{l}\text { Young-Kyun Kim et al: Effect of loading time on marginal bone loss around hydroxyapatite- } \\
\text { coated implants. J Korean Assoc Oral Maxillofac Surg 2013 }\end{array}$
\end{tabular}


Table 7. Mean crestal bone resorption by loading type in the mandible (at 12 months' loading)

\begin{tabular}{lccc}
\hline \multicolumn{1}{c}{ Loading type } & $\begin{array}{c}\text { Number } \\
\text { of implant }\end{array}$ & $\begin{array}{c}\text { Bone loss (mm), } \\
\text { mean } \pm \text { standard } \\
\text { deviation }\end{array}$ & $P$-value* \\
\hline Immediate loading & 26 & $0.27 \pm 0.61$ & 0.620 \\
Delayed loading & 7 & $0.39 \pm 0.84$ & \\
\hline
\end{tabular}

*P-values were calculated with Mann-Whitney $(\alpha=0.05)$.

Young-Kyun Kim et al: Effect of loading time on marginal bone loss around hydroxyapatitecoated implants. J Korean Assoc Oral Maxillofac Surg 2013

\section{Discussion}

HA-coated implants were introduced in the 1990s and were found to facilitate the adhesion and proliferation of osteoblasts with good coherence of serum protein and growth factors, perform well on poor-quality bony tissue by significantly increasing osseointegration between implant and bony tissue, and allow performing early loading by shortening the osseointegration period ${ }^{18-20}$. Note, however, that the coating quality and thickness varied by manufacturer, and the coating was occasionally removed during implantation. Thus, a divided HA was found to have risk of impairing osseointegration and initiating an inflammatory response ${ }^{3,21}$.

After the introduction of ion plating and ion sputtering, these problems were resolved, and the success rate has steadily increased along with advancements in HA-coated technology ${ }^{7}$. In 2005, Trisi et al. ${ }^{18}$ collected samples from the clinical specimen of 10-year-old HA-coated implants and, after histological analysis, reported loss of less than $25 \%$ for the HA-coating surface and BIC rate of $78.48 \%$. In other words, for patients receiving proper prosthetic treatment and adequate maintenance, persistent HA coating and longterm survival were possible. Many other studies also noted progress in HA-coated implants and good clinical results ${ }^{18-20}$. HAPTITE (Dentis Co., Ltd., Daegu, Korea) claimed to have resolved uneven coating and desquamation problems by reducing coating thickness to $2 \mu \mathrm{m}$ using an ultra-thin coating technique applied in vacuum at room temperature ${ }^{22}$. The Zimmer TSV-HA used in this study recorded a $97 \%$ success rate because it increased the HA crystallization rate to $97 \%$ with the application of plasma coating over HA and special MP-1 process using compressed hydration heat treatment ${ }^{23}$. Crystallization rate is an important factor in HA-coated implants because a non-crystallized HA-coated surface may melt, break, or disintegrate and cause the implant to fail. In this study, the coating thickness of Osstem TS III HA was 20-70 $\mu \mathrm{m}$, and that of Zimmer TSV-HA was 20-150 $\mu \mathrm{m}$. In both products, thermal plasma coating was applied. In X-ray diffraction (XRD) and energy dispersive spectrometer (EDS) analysis, the $\mathrm{Ca} / \mathrm{P}$ ratio of Osstem TS III HA was 1.69 , and that of Zimmer TSV-HA was 1.65. The crystallization level of Osstem TS III HA was 98\%, and that of Zimmer TSVHA was $96.3 \pm 0.6$. In ISO/TC106, HA implants must have crystallization rate of more than $62 \%$. Considering the fact that the crystallization rate of the Steri-Oss implant (Nobel Biocare AB, Göteborg, Sweden) is $73.3 \%$, both products used in this study have high crystallization rates.

For successful osseointegration under immediate loading following implantation, various tests and research have been conducted, and their results have been reported. In an animal test that compared a function group and a nonfunction group by applying a crown immediately after implantation, the microscopic examination revealed a higher rate of osseointegration in the function group. In addition, some studies found that successful osseointegration relies on loading, dental hygiene, condition of bony tissue, surgical technique, and prosthesis; thus, if the bony tissue at the implant site is healthy, tissues are subjected to minimal damage during the surgical process, and prosthesis restoration is performed carefully, osseointegration within 2 weeks is possible with early functional loading ${ }^{24}$. According to some studies, the success rate and survival rate under protocols calling for early loading and delayed loading following normal healing period do not differ greatly, but implant failure is greatly affected by the patient's overall physical condition, local factors such as poor oral hygiene, and unsuitable bony tissue at the implantation site ${ }^{25,26}$. Based on this study's results, even when applying immediate loading to HA-coated implants, the survival and bone resorption rates are not significantly different when applying delayed loading after a normal healing period.

Loading was reported not to cause independently the generation of fibrous tissue membrane, but the amount of micromotion at the bone-implant interface was more relevant. Primary stability is the most important consideration in applying immediate loading ${ }^{27}$. Calandriello and Tomatis ${ }^{27}$ reported that micromotion of more than $100 \mu \mathrm{m}$ retards healing at the bone-implant surface, whereas SzmuklerMoncler et al. ${ }^{10}$ claimed that micromotion of more than 150 $\mu \mathrm{m}$ causes the generation of fibrous tissue membrane rather than bone deposition. Therefore, reducing micromotion and increasing the success rate with immediate loading require using an implant that has been designed for easy placement and less mobility to secure primary stability ${ }^{10,27}$. 
In both groups, average alveolar bone resorption rates under different loading times were within $0.24 \pm 0.59 \mathrm{~mm}$; this was lower than the results of previously published research. According to Schincaglia et al. ${ }^{28}$, the average bone resorption rate after 1 year of loading in mandibular single implant restoration was $1.20 \pm 0.55 \mathrm{~mm}$ in the IL group and $0.77 \pm 0.38$ $\mathrm{mm}$ in the DL group. Recently, Elsyad et al. ${ }^{29}$ reported a rate of $0.91 \pm 0.63 \mathrm{~mm}$ in the IL group and $0.51 \pm 0.39$ in the DL group. For a two-piece implant, bone resorption rate of 1.5-2.0 $\mathrm{mm}$ from the 2nd surgery to 1 year of loading is regarded as normal $^{30,31}$. In 1994, Albrektsson and colleagues ${ }^{32,33}$ stressed that a successful implant should have less than $1.5 \mathrm{~mm}$ bone resorption during the first year of prosthetic treatment and subsequent annual bone resorption rate of less than 0.2 $\mathrm{mm}$. Therefore, the bone resorption rate of both groups in this study is believed to be low due to the successful early stability of the HA-coated implant, skilled surgical technique, and highly motivated patients.

This research is limited because it is neither a retrospective study nor based on a selected test group and a control group. Initial stability following implantation was not measured in all cases using Ostell Mentor (Integration Diagnostics AB, Göteborg, Sweden) or others; neither were bone resorption rates by type of prosthesis compared because we reviewed medical records and radiographs of patients who had previously received implant treatment. Another limitation of this study was its insufficient control of statistical data because each patient received a different number of implants; the location of implant placement and its length and diameter also differed. The results of this study demonstrated no significant difference, but this may be due to a number of factors in this study design. For one, the use of two different implant brands increases the difficulties in interpreting the results properly. The different implants not only had different coating properties but also different thread design and different diameters, which may influence implant stability during the healing period.

Long-term follow up after 1 year of observation is necessary, and future research with prospective study should be undertaken with only 1 implant system by strictly controlling patient age, location and number of implant placements, initial stability of implant, and follow-up surgical treatment.

\section{Conclusion}

In this retrospective research, HA-coated implant placed in the maxillary and mandibular posterior areas recorded short-term clinical success regardless of the loading time; the amount of marginal bone resorption also met the criteria for successful implantation. Mean bone loss after 1 year of loading was not significantly different between the IL group and the DL group; neither was the difference in bone resorption rates statistically significant between the two groups by type of implant system and by dental location.

The limitations of this study include not only the study period but also other variables such as surgeon's bias, different brands of implant, etc. Even with the limited study period of one year, however, this study suggests that HA-coated implants can secure a high success rate under immediate loading.

\section{References}

1. Esposito M, Hirsch JM, Lekholm U, Thomsen P. Biological factors contributing to failures of osseointegrated oral implants. (II). Etiopathogenesis. Eur J Oral Sci 1998;106:721-64.

2. de Groot K, Geesink R, Klein CP, Serekian P. Plasma sprayed coatings of hydroxylapatite. J Biomed Mater Res 1987;21:1375-81.

3. Whitehead RY, Lucas LC, Lacefield WR. The effect of dissolution on plasma sprayed hydroxylapatite coatings on titanium. Clin Mater 1993;12:31-9.

4. Overgaard S, Søballe K, Josephsen K, Hansen ES, Bünger C. Role of different loading conditions on resorption of hydroxyapatite coating evaluated by histomorphometric and stereological methods. J Orthop Res 1996;14:888-94.

5. Yoshinari M, Ozeki K, Sumii T. Properties of hydroxyapatitecoated Ti-6Al-4V alloy produced by the ion-plating method. Bull Tokyo Dent Coll 1991;32:147-56.

6. Sugiyama T, Miake Y, Yajima Y, Yamamoto K, Sakurai K. Surface observation of thin hydroxyapatite-coated implants at 80 months after insertion. J Oral Implantol 2011;37:273-8.

7. Lee JJ, Rouhfar L, Beirne OR. Survival of hydroxyapatitecoated implants: a meta-analytic review. J Oral Maxillofac Surg 2000;58:1372-9.

8. Brånemark PI, Hansson BO, Adell R, Breine U, Lindström J, Hallén $\mathrm{O}$, et al. Osseointegrated implants in the treatment of the edentulous jaw. Experience from a 10-year period. Scand J Plast Reconstr Surg Suppl 1977;16:1-132.

9. Albrektsson T. Direct bone anchorage of dental implants. J Prosthet Dent 1983;50:255-61.

10. Szmukler-Moncler S, Salama H, Reingewirtz Y, Dubruille JH. Timing of loading and effect of micromotion on bone-dental implant interface: review of experimental literature. J Biomed Mater Res 1998;43:192-203.

11. Roccuzzo M, Aglietta M, Bunino M, Bonino L. Early loading of sandblasted and acid-etched implants: a randomized-controlled double-blind split-mouth study. Five-year results. Clin Oral Implants Res 2008;19:148-52.

12. Ioannidou E, Doufexi A. Does loading time affect implant survival? A meta-analysis of 1,266 implants. J Periodontol 2005;76:1252-8.

13. Vercruyssen M, Quirynen M. Long-term, retrospective evaluation (implant and patient-centred outcome) of the two-implantsupported overdenture in the mandible. Part 2: marginal bone loss. Clin Oral Implants Res 2010;21:466-72.

14. Oh TJ, Yoon J, Misch CE, Wang HL. The causes of early implant bone loss: myth or science? J Periodontol 2002;73:322-33.

15. Cochran DL, Morton D, Weber HP. Consensus statements and 
recommended clinical procedures regarding loading protocols for endosseous dental implants. Int J Oral Maxillofac Implants 2004;19(Suppl):109-13.

16. Buser D, Mericske-Stern R, Bernard JP, Behneke A, Behneke $\mathrm{N}$, Hirt HP, et al. Long-term evaluation of non-submerged ITI implants. Part 1: 8-year life table analysis of a prospective multi-center study with 2359 implants. Clin Oral Implants Res 1997;8:161-72.

17. Cochran DL, Buser D, ten Bruggenkate CM, Weingart D, Taylor TM, Bernard JP, et al. The use of reduced healing times on ITI implants with a sandblasted and acid-etched (SLA) surface: early results from clinical trials on ITI SLA implants. Clin Oral Implants Res 2002;13:144-53.

18. Trisi P, Keith DJ, Rocco S. Human histologic and histomorphometric analyses of hydroxyapatite-coated implants after 10 years of function: a case report. Int J Oral Maxillofac Implants 2005;20:124-30.

19. Hjorting-Hansen E, Worsaae N, Lemons JE. Histologic response after implantation of porous hydroxylapatite ceramic in humans. Int J Oral Maxillofac Implants 1990;5:255-63.

20. Cook SD, Kay JF, Thomas KA, Jarcho M. Interface mechanics and histology of titanium and hydroxylapatite-coated titanium for dental implant applications. Int J Oral Maxillofac Implants 1987;2:15-22.

21. Misch CM. Hydroxylapatite-coated implants. Design considerations and clinical parameters. N Y State Dent J 1993;59:36-41.

22. Lim HS, Kim SG, Oh JS. Comparison of clinical initial stability of hydroxy-apatite coated implant and sandblasted, large-grit and acid-etched implant. J Korean Assoc Maxillofac Plast Reconstr Surg 2012;34:112-6.

23. Thierer T, Davliakos JP, Keith JD Jr, Sanders JJ, Tarnow DP, Rivers JA. Five-year prospective clinical evaluation of highly crystalline HA MP-1-coated dental implants. J Oral Implantol 2008;34:39-46.

24. Park HU, Yang JH, Lee SH. A study on the effects of early loading on the surrounding bone tissue of the dental implants. J Korean
Acad Prosthodont 1993;31:101-27.

25. Prosper L, Crespi R, Valenti E, Capparé P, Gherlone E. Fiveyear follow-up of wide-diameter implants placed in fresh molar extraction sockets in the mandible: immediate versus delayed loading. Int J Oral Maxillofac Implants 2010;25:607-12.

26. Cannizzaro G, Leone M. Restoration of partially edentulous patients using dental implants with a microtextured surface: a prospective comparison of delayed and immediate full occlusal loading. Int J Oral Maxillofac Implants 2003;18:512-22.

27. Calandriello R, Tomatis M. Immediate occlusal loading of single lower molars using Brånemark System Wide Platform TiUnite implants: a 5-year follow-up report of a prospective clinical multicenter study. Clin Implant Dent Relat Res 2011;13:311-8.

28. Schincaglia GP, Marzola R, Giovanni GF, Chiara CS, Scotti R. Replacement of mandibular molars with single-unit restorations supported by wide-body implants: immediate versus delayed loading. A randomized controlled study. Int J Oral Maxillofac Implants 2008;23:474-80.

29. Elsyad MA, Al-Mahdy YF, Fouad MM. Marginal bone loss adjacent to conventional and immediate loaded two implants supporting a ball-retained mandibular overdenture: a 3-year randomized clinical trial. Clin Oral Implants Res 2012;23:496-503.

30. Hermann JS, Buser D, Schenk RK, Schoolfield JD, Cochran DL. Biologic Width around one- and two-piece titanium implants. Clin Oral Implants Res 2001;12:559-71.

31. Cochran DL, Nummikoski PV, Schoolfield JD, Jones AA, Oates TW. A prospective multicenter 5-year radiographic evaluation of crestal bone levels over time in 596 dental implants placed in 192 patients. J Periodontol 2009;80:725-33.

32. Albrektsson T, Isidor F. Consensus report of session IV. In: Lang NP, Karring T, eds. Proceedings of the 1st European workshop on periodontology. London: Quintessence Publishing; 1994:365-9.

33. Albrektsson T, Zarb G, Worthington P, Eriksson AR. The longterm efficacy of currently used dental implants: a review and proposed criteria of success. Int J Oral Maxillofac Implants 1986;1:11-25. 